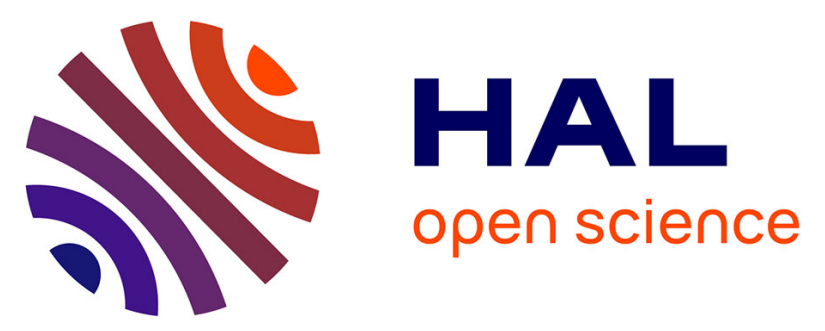

\title{
Transformation of Discrete Amorphous Aluminosilicate Nanoparticles into Nanosized Zeolites
}

Hailing Guo, Lei Zhao, Charlotte Martineau-corcos, Franck Fayon, Jasmine Viger-gravel, Hussein Awala, Philippe Boullay, Julien Grand, Aurelie Vicente, Jean-pierre Gilson, et al.

\section{To cite this version:}

Hailing Guo, Lei Zhao, Charlotte Martineau-corcos, Franck Fayon, Jasmine Viger-gravel, et al.. Transformation of Discrete Amorphous Aluminosilicate Nanoparticles into Nanosized Zeolites. Advanced Materials Interfaces, 2020, pp.2000634 (1-7). 10.1002/admi.202000634 . hal-02893829

\section{HAL Id: hal-02893829 \\ https://hal.science/hal-02893829}

Submitted on 18 Nov 2020

HAL is a multi-disciplinary open access archive for the deposit and dissemination of scientific research documents, whether they are published or not. The documents may come from teaching and research institutions in France or abroad, or from public or private research centers.
L'archive ouverte pluridisciplinaire HAL, est destinée au dépôt et à la diffusion de documents scientifiques de niveau recherche, publiés ou non, émanant des établissements d'enseignement et de recherche français ou étrangers, des laboratoires publics ou privés. 


\section{Transformation of Discrete Amorphous Aluminosilicate Nanoparticles into Nanosized Zeolites}

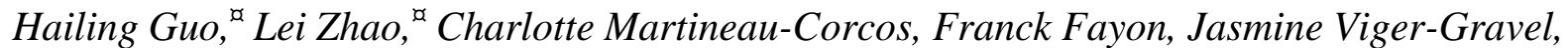
Hussein Awala, Philippe Boullay, Julien Grand, Aurélie Vicente, Jean-Pierre Gilson, and Svetlana Mintova*

Prof. H. Guo, L. Zhao, Prof. S. Mintova

State Key Laboratory of Heavy Oil Processing, Key Laboratory of Catalysis, China National Petroleum Corp. (CNPC), China University of Petroleum (East China), 66 Changjiangxi Road, Qingdao 266555, P. R. China.

E-mail: guohl@upc.edu.cn

Dr. H. Awala, Dr. J. Grand, Dr. A. Vicente, Prof. J.-P. Gilson, Prof. S. Mintova

Normandie Univ, ENSICAEN, UNICAEN, CNRS, LCS,

6 boulevard Maréchal Juin 14000 Caen, France.

E-mail: mintova@ensicaen.fr

Dr. C. Martineau-Corcos

MIM, Institut Lavoisier de Versailles (ILV), CNRS UMR8180, Université de Versailles Saint-Quentin en Yvelines (UVSQ),

45 avenue des États-Unis, 78035 Versailles, France.

Dr. C. Martineau-Corcos, Dr. F. Fayon

CEMHTI, CNRS UPR3079,

1D avenue de la recherche scientifique, 45071 Orléans 2, France.

Dr. J. Viger-Gravel,

Centre de Resonance Magnétique Nucléaire à Très Hauts Champs de Lyon (CRMN) FRE 2034,

CNRS/Université Claude, Bernard Lyon 1/ENS Lyon,

5, rue de la Doua, 69100, Villeurbanne, France

Dr. P. Boullay

Normandie Univ, ENSICAEN, UNICAEN, CNRS, CRISMAT,

6, boulevard Maréchal Juin, 14000 Caen, France

Keywords: amorohous nanoparticles, selective transformation, nanosized zeolites, alkali suspensions; inorganic cations

The effect of amorphous aluminosilicate precursor nanoparticles on the formation the nanosized zeolites with Faujasite (FAU) and Sodalite (SOD) type frameworks is illustrated using a new synthetic strategy to prepare nanosized zeolites with tailored particle size distribution, morphology and structure. This two-steps synthesis procedure includes: (1) the formation of colloidal suspensions followed by separation of the amorphous precursor nanoparticles, (2) their subsequent transformation into nanosized crystals by treatment with alkali suspensions $(\mathrm{NaOH})$ solutions only. The selective transformation of the amorphous nanoparticles into FAU 
and SOD nanosized crystals is studied at atomistic and microscopic levels using ${ }^{29} \mathrm{Si}$ and ${ }^{23} \mathrm{Na}$ NMR spectroscopy, XRD and $\mathrm{N}_{2}$ physisorption, respectively. The presence of sodalite cages occluding highly mobile sodium in the amorphous nanoparticles is confirmed by ${ }^{23} \mathrm{Na}-{ }^{1} \mathrm{H} D$ HMQC NMR spectroscopy. The subsequent treatment of these amorphous precursor particles with aqueous sodium hydroxide illustrates that the cations are not only charge compensators but also inorganic templates stabilizing sodalite cages during the long-range ordering in the amorphous particles.

\section{Introduction}

Nanosized zeolites with crystals dimensions below $200 \mathrm{~nm}$ and substantial external surface areas provide more accessible active sites and short diffusion pathways. They are not only beneficial for catalysis and gas separation but also for advanced applications in medicine, semiconducting industry, food industry, fine chemicals. ${ }^{[1-5]}$ To date, only a few approaches for the preparation of nanosized zeolite are developed such as the use of organic template, ${ }^{[6]}$ spaceconfined syntheses, ${ }^{[7]}$ organic-template-free synthetic route ${ }^{[8]}$ and seed approach. ${ }^{[9]}$ Recently, our group reported the syntheses with high solid yields of FAU and EMT nanosized zeolites without organic structure-directing agent. ${ }^{[10,11]}$ The original size of amorphous aluminosilicate precursor nanoparticles, in clear solutions, was fully preserved during crystallization. Such onestep hydrothermal synthesis promotes simultaneous reactions including hydrolysis and/or condensation of silica and alumina species, formation and phase transfer of amorphous particles, nucleation, and crystal growth. ${ }^{[12-14]}$ The careful control of all these steps allows to control phase purity, particle morphology, size, and chemical composition; the properties of the resulting crystalline zeolites are therefore partially predetermined before the onset of crystal growth. ${ }^{[15,16]}$ This highlights that nucleation events are critical to control the properties of the zeolites harvested, however, finer details of such a mechanisms are lacking and deserve more attention.

In this paper, we present deeper insights on the effect of amorphous precursor nanoparticles to prepare nanosized FAU type (zeolite X) and sodalite (SOD) crystals by their direct transformation under alkali treatment only. This allows to identify similarities between amorphous precursor nanoparticles and the derived nanosized zeolite crystals at atomistic and microscopic levels. This synthesis procedure involves two steps: (1) the preparation of a template-free precursor suspension and their harvesting of uniform amorphous precursor nanoparticles, (2) their subsequent transformation into FAU or SOD nanocrystals under a welldefined treatment with pure alkali suspensions (sodium hydroxide, $\mathrm{NaOH}$ ). As a result, the 
nanosized crystals harvested preserve the size and morphology of their precursor nanoparticles while possessing all the attributes of porous crystal.

\section{Results and Discussion}

The isolated amorphous precursor nanoparticles (sample S1 in Table 1) subjected to posttreatment with alkali solutions $(\mathrm{NaOH}, \mathrm{LiOH}, \mathrm{KOH})$ are summarized in Table 1 . These amorphous nanoparticles were transformed into nanosized FAU (sample S2 in Table 1) and SOD nanocrystals (sample S3 in Table 1) following the procedure described in the Experimental section. As shown in Figure 1a, the precursor nanoparticles do not exhibit any Bragg peaks indicating its amorphous nature. The precursors particles treated with $5 \mathrm{wt} . \%$ and 23 wt. $\% \mathrm{NaOH}$ at $60{ }^{\circ} \mathrm{C}(20 \mathrm{~h}$ and $40 \mathrm{~h})$ yield crystalline and pure FAU and SOD nanocrystals, respectively (Figure 1b, c). While the amorphous precursor nanoparticles post-treated with $\mathrm{LiOH}(5$ wt.\%) or KOH (5 wt.\%) (samples S4 and S5 in Table 1) did not show any XRD diffraction peaks (Figure S1a, b). The amorphous precursor nanoparticles post-treated with a mixture of $\mathrm{LiOH} / \mathrm{NaOH}$ and $\mathrm{KOH} / \mathrm{NaOH}$ (samples S6 and $\mathrm{S} 7$ in Table 1) transform to FAU phase (Figure S1c, d), indicating that $\mathrm{Na}^{+}$is the only inorganic template responsible for the transformation of amorphous precursor nanoparticles to zeolite crystals. The Si/Al ratio, determined by ICP, and EDS (Table S1), of the FAU and SOD nanocrystals are 1.1 and 1.3, while the one of the amorphous precursor is 1.8. TEM and SEM pictures, Figure 2, indicate a size of the crystalline particles (FAU and SOD) of about 20-25 nm and a shape similar to the amorphous nanoparticles (Figure 2 a-f). However, nanosized FAU and SOD particles have sharper edges and contain fringes revealing their crystalline nature; the [111] oriented FAU and [110] oriented SOD nanocrystals are shown in Figure 2 h,f. The high resolution TEM picture of the precursor particle (Figure $2 \mathrm{~g}$ ) confirms the typical amorphous nature of the material. The remarkable similarities in the size and morphology between amorphous and crystalline nanoparticles verify the effect of the precursor nanoparticles at a microscopic scale.

The $\mathrm{N}_{2}$ sorption on the amorphous precursors and their derived FAU and SOD nanosized crystals is reported in Figure 3. The amorphous nanoparticles exhibit a classic IV isotherm with a large H1-type hysteresis, the unusually high mesoporosity is attributed to their packing resulting in mesopores with a diameter of $20 \mathrm{~nm}$. The FAU nanocrystals exhibit a mix of Type I and IV isotherms with a large H1-type hysteresis; such a feature is indicative of textural pores due to the close packing of monodispersed and well-shaped nanocrystals. As shown in Table S2, the total pore volumes of 
amorphous precursor nanoparticles, FAU and SOD nanosized crystals are 0.61, 1.36 and $0.43 \mathrm{~cm}^{3} \mathrm{~g}^{-1}$, respectively. The main contribution in porosity for the amorphous nanoparticles and SOD nanocrystals is due to their mesopore volume, 0.61 and 0.43 $\mathrm{cm}^{3} \mathrm{~g}^{-1}$, respectively. The external surface area of the amorphous precursor nanoparticles, FAU and SOD nanosized crystals are 260, 230 and $160 \mathrm{~m}^{2} / \mathrm{g}$, respectively. The similarities in external surface areas and mesopore volumes of the three samples indicate the similarities of both surface features and size between the amorphous and crystalline nanoparticles.

Such similarities found between the amorphous precursor nanoparticles and the crystalline matter requires further investigation at the atomistic level. The ${ }^{29} \mathrm{Si}$ magic-angle spinning (MAS) NMR spectra of the amorphous precursor nanoparticles, FAU and SOD nanosized crystals are presented in Figure 4. The spectrum of amorphous precursor nanoparticles consists of a broad peak at -88.2 ppm while the FAU exhibits three peaks at -84.8 ppm, -89.8 ppm and -95.1 ppm, assigned to $\mathrm{Si}-(\mathrm{OAl})_{4}\left(\mathrm{Q}_{4}^{4}\right), \mathrm{Si}(\mathrm{OAl})_{3}(\mathrm{OSi})\left(\mathrm{Q}^{4}{ }_{3}\right)$ and $\mathrm{Si}-(\mathrm{OAl})_{2}(\mathrm{OSi})_{2}\left(\mathrm{Q}^{4}{ }_{2}\right)$ units, respectively (Figure $4 \mathrm{~b}$ ). The spectrum of SOD shows one narrow peak at $-88.5 \mathrm{ppm}$ corresponding to $\mathrm{Si}(\mathrm{OAl})_{3}(\mathrm{OSi})\left(\mathrm{Q}_{3}^{4}\right)$ unit. The $\mathrm{Si} / \mathrm{Al}$ ratios of $\mathrm{FAU}$ and $\mathrm{SOD}$ nanosized zeolite determined by ${ }^{29} \mathrm{Si}$ NMR (Figure 4) are 1.14 and 1.33 , which is consistent with the ICP result. Further confirmation of the amorphous nature of the precursor nanoparticles were provided by IR spectroscopy. A band at $460 \mathrm{~cm}^{-1}$ is assigned to structure-insensitive T-O bending modes of tetrahedral $\mathrm{TO}_{4}$ units (Figure 5a). While another T-O mode at $565 \mathrm{~cm}^{-1}$ related to the presence of the double six rings that are part of the FAU structure is observed only in the spectrum of the nanosized FAU (Figure 5b). The band in the range $980-1010 \mathrm{~cm}^{-1}$ corresponding to the T-O$\mathrm{T}$ mode is used as an indicator to determine the $\mathrm{Si} / \mathrm{Al}$ ratio of the materials; that results indicate that the denser SOD crystalline nanoparticles have higher $\mathrm{SiO}_{2} / \mathrm{Al}_{2} \mathrm{O}_{3}$ in comparison to the $\mathrm{FAU}$ zeolite nanocrystals.

To get further information, ${ }^{23} \mathrm{Na}$ MAS and multiple-quantum MAS (MQMAS) NMR was used, as it was previously shown that this technique has the potential to shed more light on the nature of the structural units present in the amorphous precursor nanoparticles. ${ }^{[17]}{ }^{23} \mathrm{Na}$ MAS NMR spectra of dehydrated amorphous precursor nanoparticles, FAU and SOD nanocrystals are recorded at two magnetic fields of 11.7 and $20.0 \mathrm{~T}$ (Figure S2, Table S3). These results enable us to distinguish between the effects of second order quadrupolar interaction and chemical shift distribution. Several resonances are observed for the SOD and FAU nanocrystals, some with large quadrupolar coupling constant $\mathrm{C}_{\mathrm{Q}}$, in agreement with data reported earlier. ${ }^{[18-}$ ${ }^{21}$ The ${ }^{23} \mathrm{Na}$ MAS NMR spectrum of the amorphous precursor nanoparticles consists of a single 
resonance centred at $10 \mathrm{ppm}$ dominated by a large chemical shift distribution (ca $14 \mathrm{ppm}$ ). Despite the high resolution of the NMR data, the potential similarity of the ${ }^{23} \mathrm{Na}$ resonance between the amorphous precursor nanoparticles and those of SOD or FAU nanocrystals is not clear. In Figure 6, ${ }^{23} \mathrm{Na}-{ }^{1} \mathrm{H} D$-HMQC NMR spectra indicate spatial proximity between sodium cations and protons for the three samples. The ${ }^{23} \mathrm{Na}-{ }^{1} \mathrm{H} D$-HMQC NMR spectra of the SOD and FAU nanosized crystals are very similar, except for the presence of an additional acidic proton (at $9 \mathrm{ppm}$ ) in close vicinity of some Na cations in SOD. However, the amount of this acid proton in SOD remains very low, as evidenced from the ${ }^{1} \mathrm{H}$ MAS quantitative spectrum (Figure S4). In the ${ }^{23} \mathrm{Na}-{ }^{1} \mathrm{H} D$-HMQC NMR spectrum of the amorphous precursor nanoparticles, the signals fall in the same range as the main signals of SOD and FAU nanosized crystals but show different intensities with respect to that of FAU. Indeed, when comparing the indirect ${ }^{1} \mathrm{H}$ projections of the $D$-HMQC NMR spectra with the 1D ${ }^{1} \mathrm{H}$ MAS NMR spectra, one can see that the two ${ }^{1} \mathrm{H}$ spectra of FAU are almost identical, indicating short distances between all protons and all sodium atoms within the zeolite framework. In contrast, for SOD and the amorphous sample, a strong decrease of the ${ }^{1} \mathrm{H}$ signal located at $1.3 \mathrm{ppm}$ is observed in the $D$-HMQC NMR spectrum (Figure S4), indicating a more remote spatial proximity between sodium cations and these protons. Since the only difference between FAU and SOD is the presence of supercages in FAU, it could be assumed that the presence of supercages in FAU favours proton-sodium spatial proximity leading to homogeneous ${ }^{1} \mathrm{H}_{-}{ }^{23} \mathrm{Na}$ dipolar interactions between all sodium cations and protons. The strong similarity between the ${ }^{1} \mathrm{H}$ and ${ }^{23} \mathrm{Na}$ proximity patterns of the amorphous particles with that of SOD (i.e., the non-homogeneous distribution of proton-sodium proximities) could suggest that, like in SOD, no supercages are formed in the amorphous particles, hence they only contain small sodalite cages.

To understand why smaller ${ }^{23} \mathrm{Na}$ quadrupolar interactions are observed in the amorphous precursor nanoparticles compared with the SOD and FAU nanosized crystals, ${ }^{23} \mathrm{Na}$ MAS NMR spectra are recorded at low temperature $\left(-173{ }^{\circ} \mathrm{C}, 18.8 \mathrm{~T}\right)$ to quench potential cationic (sodium) mobility (Figure 7, Figure S3). The striking feature of the resulting ${ }^{23} \mathrm{Na}$ spectra is a broader resonance in the amorphous precursor nanoparticles compared to room temperature while the ${ }^{23} \mathrm{Na}$ linewidth of the FAU and SOD peaks remains constant. This indicates motional averaging at room temperature for the amorphous precursor, hence a high sodium mobility in the amorphous particles consistent with the observed low $\mathrm{C}_{\mathrm{Q}}$ value. The high sodium mobility could be due to the occurrence of not fully closed sodalite cages in the amorphous precursor particles, allowing fast jump of sodium cations between individual cages. These NMR results 
clearly demonstrate that the amorphous precursor nanoparticles contain sodalite cages with occluded but mobile $\mathrm{Na}$ cations. Further treatment of these amorphous nanoparticles with 5 wt. $\%\left(60{ }^{\circ} \mathrm{C}, 20 \mathrm{~h}\right)$ and 23 wt. $\%\left(60{ }^{\circ} \mathrm{C}, 40 \mathrm{~h}\right) \mathrm{NaOH}$ solutions, leads to their respective transformation into nanosized FAU and SOD nanocrystals. Theoretical and experimental studies on the stabilizing role of inorganic cations for SBU were reported earlier. ${ }^{[22-23]}$ The treatment of the amorphous precursor particles with $\mathrm{Na}^{+}$ highlights that, in addition to its role as a charge compensator for $\mathrm{Si}-(\mathrm{OAl})_{4}^{-}$units, it is an inorganic template stabilizing the secondary building units (SOD cages) during the crystallization of the amorphous particles.

In order to verify the similarities between amorphous and crystalline structures, another amorphous precursor sample was prepared but not subjected to aging (sample named as amorphous precursor-0). The amorphous precursor-0 sample was treated at the same conditions, i.e. with $5 \mathrm{wt} . \% \mathrm{NaOH}$ at $60^{\circ} \mathrm{C}$ for $20 \mathrm{~h}$. The XRD patterns of both the amorphous precursor- 0 and the sample after treatment do not contain any Bragg peaks as shown in Figure S4b. This study confirmed that the aged amorphous precursor sample with the secondary build units (SOD cages and single six membered rings) are essential for the formation of the crystalline materials. Therefore, we conclude that the amorphous precursor-0 without secondary building units (SOD cages and single six membered ring) cannot be transformed to zeolite crystals at same condition, which further verify the memory effect of structure of the amorphous precursor particles with SOD cages.

\section{Conclusion}

In summary, a new strategy to design nanosized crystals with a tailored size distribution and morphology from amorphous precursor nanoparticles is presented. More importantly, the formation and structural evolution of amorphous precursor nanoparticles into crystalline nanomaterials show that the properties of the amorphous particles determine those of the derived crystalline phases. The templating role of the sodium cations is responsible for the stabilization of framework structures with different framework density. A high sodium concentration produces denser phase such as SOD, while lower sodium content stabilizes the more open FAU structure. The properties of those derived crystalline products (size, morphology and chemical composition) are therefore predetermined before the crystallization. 
The synthesis method can in principle be extended to other microporous materials including aluminophosphates, metal-containing silicates, aluminosilicates, and thus opens the route to the controlled synthesis of materials with predetermined properties such as size, porosity, morphology and chemical compositions.

\section{Experimental Section}

\subsection{Synthetic procedures}

\subsubsection{Chemicals and reagents}

Al powder (325 mesh, 99.5\%, Alfa Aesar), $\mathrm{NaOH}$ (Sigma-Aldrich, 97\%) $\mathrm{SiO}_{2}$ (Ludox-HS 30, 30 wt.\% $\mathrm{SiO}_{2}, \mathrm{pH}=9.8$, Aldrich), $\mathrm{LiOH}$ (Aladdin, 99.9\%), $\mathrm{KOH}$ (Aladdin, 90\%).

\subsubsection{Preparation of amorphous precursor nanoparticles}

The amorphous precursor nanoparticles were prepared from a clear precursor suspension with a molar composition: 9-12.5 Na2 $\mathrm{O}$ : 0.59-0.7 $\mathrm{Al}_{2} \mathrm{O}_{3}$ : 3.5-10 $\mathrm{SiO}_{2}$ : 160$170 \mathrm{H}_{2} \mathrm{O}$. The initial reactants were used to prepare two solutions denoted A and $\mathrm{B}$. Solution A was prepared by dissolving $5 \mathrm{~g}$ of $\mathrm{NaOH}$ (Sigma-Aldrich) in $10 \mathrm{~g}$ double distilled water $\left(\mathrm{dd} \mathrm{H}_{2} \mathrm{O}\right.$ ) followed by slow addition of 0.5-0.9 g aluminum powder (325 mesh, $99.5 \%$, Alfa Aesar). Solution B was prepared by mixing of $10 \mathrm{~g}$ colloidal silica (Ludox-HS 30, 30 wt.\% $\mathrm{SiO}_{2}, \mathrm{pH}=9.8$, Aldrich) with $9.5 \mathrm{~g} \mathrm{NaOH}$ and $26 \mathrm{~g} \mathrm{dd} \mathrm{H}_{2} \mathrm{O}$; as a result, a turbid suspension was obtained. In order to transform the turbid into water clear suspension, the container was placed in an oven at $100{ }^{\circ} \mathrm{C}$ for 5 minutes. Solution A was added drop wise under vigorously stirring to the solution B; during the mixing, solution B was kept in ice. The resulting clear suspension was kept $24 \mathrm{~h}$ at room temperature. The aluminosilicate precursor nanoparticles were isolated by centrifugation (20.000 rpm) and purified with distilled water $(\mathrm{pH}=8)$, then subjected to freeze drying. The amorphous precursor suspension without aging at room temperature is named as amorphous precursor-0.

\subsubsection{Synthesis of FAU nanosized crystals}

$500 \mathrm{mg}$ amorphous precursor nanoparticles in power form were mixed with $10 \mathrm{ml}$ $\mathrm{NaOH}$ solution; the concentration of alkali solutions was varied from 2 wt. $\%$ to $10 \mathrm{wt} . \%$. The suspension was heated at $60{ }^{\circ} \mathrm{C}$ for $20 \mathrm{~h}$. The nanosized crystals were collected by 
centrifugation and washed using high speed centrifugation; samples are presented in Table 1.

\subsubsection{Synthesis of SOD nanosized crystals}

The SOD nanosized crystals were synthesized from the same amorphous precursor nanoparticles following the procedure described for FAU zeolite, however the concentration of $\mathrm{NaOH}$ varied from 15 wt.\% to $37 \mathrm{wt} . \%$. The suspensions were heated at $60^{\circ} \mathrm{C}$ for $40 \mathrm{~h}$.

\subsection{Characterization}

Powder samples were measured using a PANalytical X'Pert Pro diffractometer with $\mathrm{CuK} \alpha$ monochromatized radiation $(\lambda=1.5418 \AA)$. The crystal size, morphology and crystallinity of solids were determined by a JEOL JSM-7900F scanning electron microscope (SEM) and a FEI LaB6 TECNAI G2 30UT transmission electron microscope (TEM) operated at $300 \mathrm{kV}$. The distribution of the elements of the samples was measured by EDS-SEM using JEOL-7900F SEM and Oxford Instruments X-MaxN Energy-Dispersive Spectroscopy. The chemical composition of the FAU samples was determined by inductively coupled plasma (ICP) optical emission spectroscopy using a Varian ICP-OES 720-ES. Nitrogen adsorption/desorption isotherms were measured using Micrometrics ASAP 2020 volumetric adsorption analyzer.

Solid State ${ }^{29}$ Si NMR spectra were recorded on a Bruker Avance 400 (9.4 T) spectrometer using $4 \mathrm{~mm}-\mathrm{OD}$ zirconia rotors and a spinning frequency of $12 \mathrm{kHz}$. The room temperature ${ }^{23} \mathrm{Na}$ MAS (single pulse) NMR spectra were recorded at two magnetic fields of 11.7 (Bruker Avance, ${ }^{23} \mathrm{Na}$ Larmor frequency of $132.3 \mathrm{MHz}$, MAS $20 \mathrm{kHz}$ ) and 20.0 T (Bruker Avance III, ${ }^{23} \mathrm{Na}$ Larmor frequency of $224.9 \mathrm{MHz}$, MAS $32 \mathrm{kHz}$ ). The ${ }^{23} \mathrm{Na}$ MQMAS (z-filter sequence, ${ }^{[24]}$ MAS $32 \mathrm{kHz}$ for amorphous nanoparticles and FAU, MAS $60 \mathrm{kHz}$ for SOD) and ${ }^{23} \mathrm{Na}-{ }^{1} \mathrm{H} D$-HMQC, ${ }^{[25]}\left(\mathrm{R} 4{ }_{1}{ }^{2}\right.$ recoupling, ${ }^{[26]} 1.125 \mathrm{~ms}$ recoupling time, MAS $32 \mathrm{kHz}$ ) were recorded at $20.0 \mathrm{~T}$. Recycle delay of $0.3 \mathrm{~s}$ were used. The low temperature $\left(-173{ }^{\circ} \mathrm{C}\right){ }^{23} \mathrm{Na}$ MAS (single pulse) NMR spectra were recorded at 18.8 T (Bruker Avance III, ${ }^{23} \mathrm{Na}$ Larmor frequency of $211.5 \mathrm{MHz}$, MAS 5 $\mathrm{kHz}$ ). All samples were dehydrated at $250{ }^{\circ} \mathrm{C}$ under vacuum prior to measurement. Dry $\mathrm{N}_{2}$ was used as bearing and drive gases ensuring no rehydration of the samples during the NMR measurements. The ${ }^{23} \mathrm{Na}$ chemical shifts are referenced to a $0.1 \mathrm{M}$ solution of $\mathrm{NaNO}_{3}$. All spectra were analyzed using the Dmfit software. ${ }^{[27]}$ 


\section{Acknowledgements}

The authors gratefully acknowledged funding from Thousand Talents Program for Foreign Experts (WQ20152100284), the French-China Science Foundation (FFCSA), the National Natural Science Foundation of China (Grant No. U1862118), and the State Key Laboratory of Advanced Technology for Materials Synthesis and Processing (Wuhan University of Technology) (No. 2018-KF-13) and the International Associated Laboratory (LIA)-Zeolites. Financial support from the IR-RMN-THC Fr3050 CNRS for conducting the research is gratefully acknowledged. Hailing Guo and Lei Zhao contributed equally to this work.

\section{References}

[1] T. Zhang, X. Chen, G. Chen, M. Chen, R. Bai, M. Jia, J. Yu, J. Mater. Chem. A 2018, 6, 9473.

[2] M. Pan, H. M. Omar, S. Rohani, Nanomaterials 2017, 7, 195.

[3] B. Hossein-Nia, S. Khorram, H. Rezazadeh, A. Safaiyan, R. Ghiasi, A. TarighatEafaniani, Adv. Pharm. Bull. 2018, 8, 211.

[4] X. Zhang, J. Sun, J. Liu, H. Xu, B. Dong, X. Sun, T. Zhang, S. Xu, L. Xu, X. Bai, S. Zhang, S. Mintova, H. Song, Sensor Actuat. B-Chem. 2018, 255, 2919.

[5] M. Shete, M. Kumar, D. Kim, N. Rangnekar, D. Xu, B. Topuz, K. V. Agrawal, E. Karapetrova, B. Stottrup, S. Al-Thabaiti, S. Basahel, K. Narasimharao, J. D. Rimer, M. Tsapatsis, Angew. Chem. Int. Edit. 2017, 56, 535.

[6] G. Chen, Q. Sun, J. Yu, Chem. Commun. 2017, 53, 13328.

[7] L. Shi, J. Wang, N. Li, S. Lin, J. Alloy. Compo. 2017, 695, 2488.

[8] M. Borel, M. Dodin, T. J. Daou, N. Bats, B. Harbuzaru, J. Patarin, Cryst. Growth Des. 2017, 17, 1173.

[9] C. Li, M. Moliner, A. Corma, Angew. Chem. Int. Edit. 2018, 57, 15330.

[10] H. Awala, J.-P. Gilson, R. Retoux, P. Boullay, J.-M. Goupil, V. Valtchev, S. Mintova, Nat. Mater. 2015, 14, 447.

[11] E.-P. Ng, D. Chateigner, T. Bein, V. Valtchev, S. Mintova, Science 2012, 335, 70.

[12] M. W. Anderson, J. T. Gebbie-Rayet, A. R. Hill, N. Farida, M. P. Attfield, P. Cubillas, V. A. Blatov, D. M. Proserpio, D. Akporiaye, B. Arstad. J. D. Gale, Nature 2017, 544, 456.

[13] I. I. Ivanova, Y. G. Kolyagin, I. A. Kasyanov, A. V. Yakimov, T. O. Bok, D. N. Zarubin, Angew. Chem. Int. Edit. 2017, 56, 15344. 
[14] Y. Zhao, H. Zhang, P. Wang, F. Xue, Z. Ye, Y. Zhang, Y. Tang, Chem. Mater. 2017, 29, 3387.

[15] L. Liu, H. Wang, Z. Wang, L. Zhu, L. Huang, L. Yu, J. Fan, Y. Yao, S. Liu, J. Zou, X. Zeng, Chem. Commun. 2018, 54, 9821.

[16] M. Houlleberghs, E. Breynaert, K. Asselman, E. Vaneeckhaute, S. Radhakrishnan, M. W. Anderson, F. Taulelle, M. Haouas, J. A. Martens, C. E. A. Kirschhock, Micropore. Mesopor. Mat. 2019, 274, 379.

[17] S. Antonijevic, S. E. Ashbrook, R. I. Walton, S. Wimperis, J. Mater. Chem., 2002, 12, 1469.

[18] S. Caldarelli, A. Buchholz and M. Hunger, J. Am. Chem. Soc. 2001, 123, 7118.

[19] H. A. M. Verhultst, W. J. J. Welters, G. Vorbeck, L. J. M. van de Ven, V. H. J. de Beer, R. A. van Santen, J. W. de Haan, J. Phys. Chem. 1994, 98, 7056.

[20] Z. Zhao, Y. Xing, S. Li, X. Meng, F. Xiao, R. McGuire, A.-N. Parvulescu, U. Mueller, W. Zhang, J. Phys. Chem. C 2018, 122, 9973.

[21] M. Hunger, G. Engelhardt, H. Koller, J. Weitkamp, Solid State Nucl. Mag. 1993, 2, 111.

[22] F. D. S. Vilhena, R. M. Serra, A. V. Boix, G. B. Ferreira, J. W. D. M. Carneiro, Comput. Theor. Chem. 2016, 1091, 115.

[23] D. A. Faux, W. Smith, T. R. Forester, J. Phys. Chem. B 1997, 101, 1762.

[24] J. P. Amoureux, C. Fernandez, S. Steuernagel, J. Magn. Reson. Ser. A 1996, 123, 116. [25] (a) Z. Gan, Journal of Magnetic Resonance, 2007, 184, 39; (b) J. Trebosc, B. Hu, J. P. Amoureux, Z. Gan, J. Magn. Reson. Ser 2007, 186, 220.

[26] (a) M. H. Levitt, T. G. Oas, R. G. Griffin, Isr. J. Chem. 1988, 28, 271; (b) A. Brinkmann, A. Kentgens, J. Am. Chem. Soc. 2006, 128, 14758.

[27] D. Massiot, F. Fayon, M. Capron, I. King, S. Le Calvé, B. Alonso, J.-O. Durand, B. Bujoli, Z. Gan, G. Hoatson, Magn. Reson. Chem. 2002, 40, 70. 


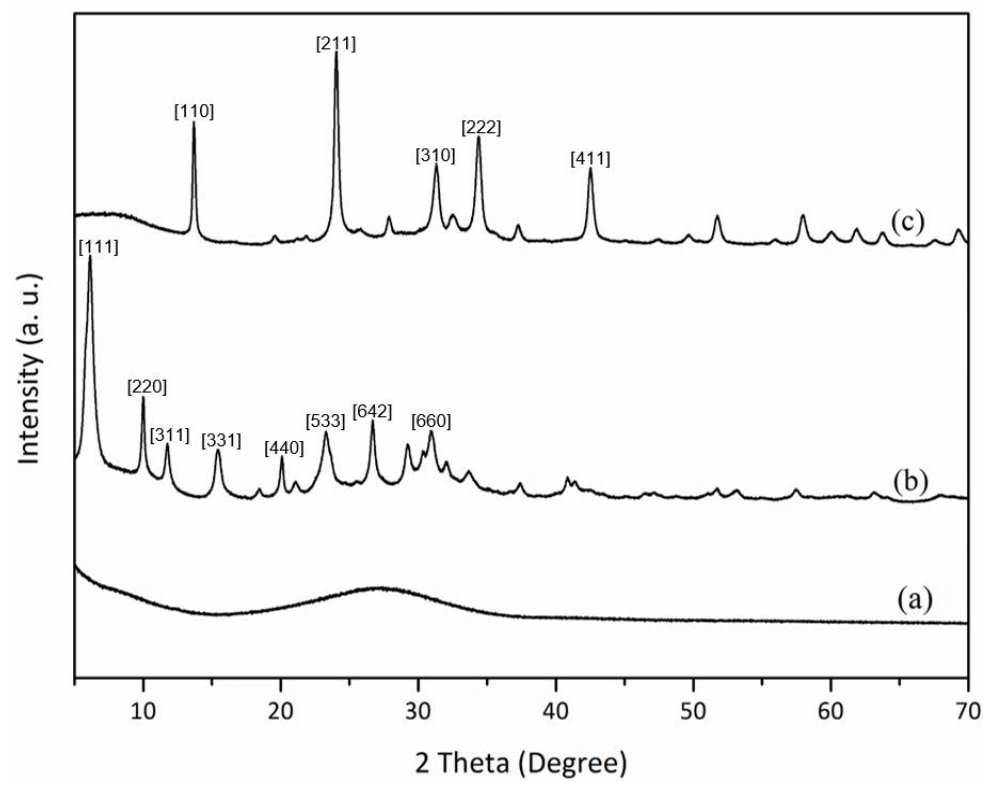

Figure 1. XRD patterns of (a) amorphous precursor nanoparticles, (b) FAU and (c) SOD nanosized crystals. 

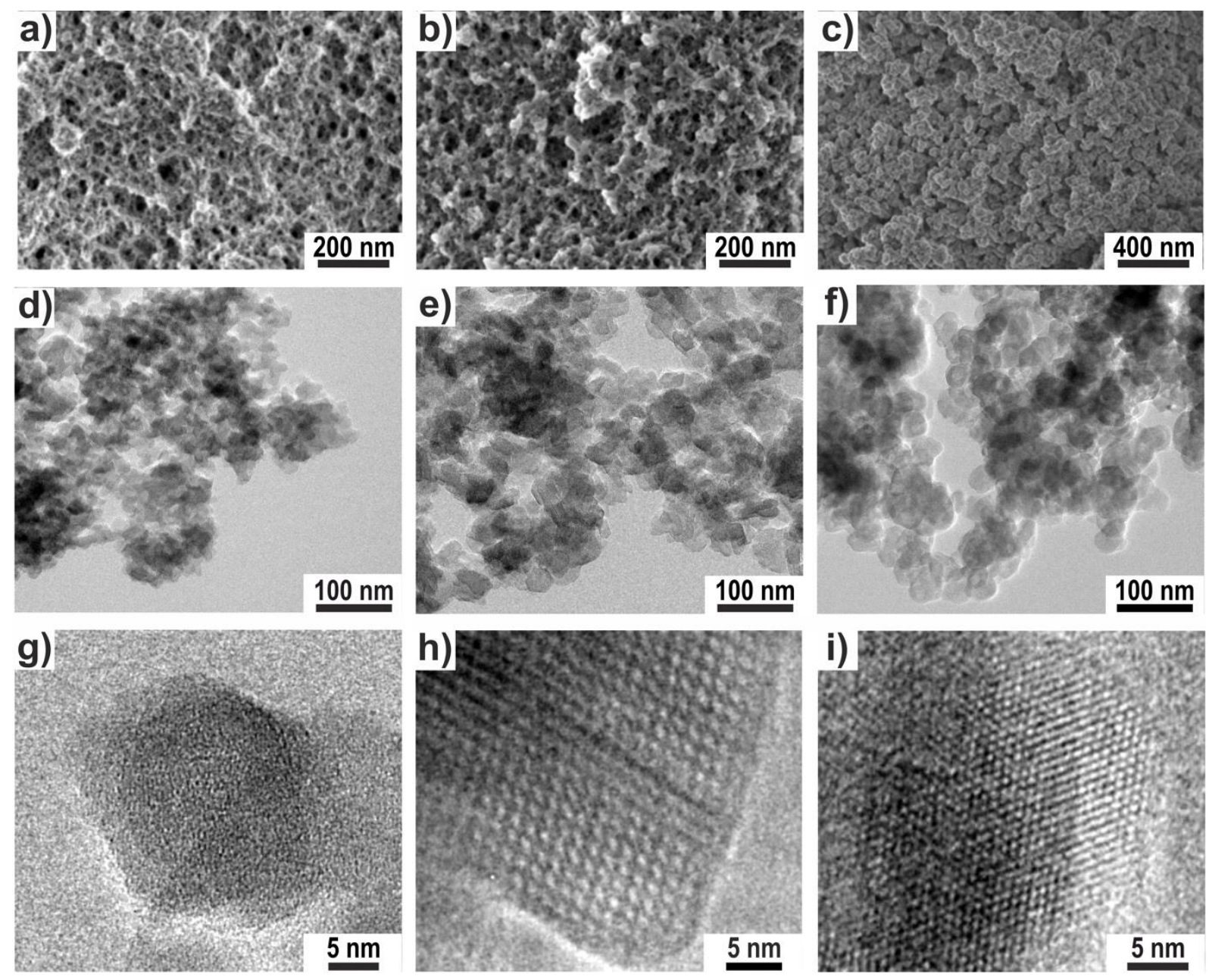

Figure 2. SEM images of (a) amorphous precursor nanoparticles, (b) FAU and (c) SOD nanocrystals. TEM images of (d) amorphous precursor nanoparticles, (e) FAU and (f) SOD nanocrystals (Scale bar, $\mathrm{M}=100 \mathrm{~nm}$ ), and high resolution TEM images of $(\mathrm{g})$ amorphous particle, (h) [111] oriented FAU and (i) [110] oriented SOD crystals (Scale bar $=5 \mathrm{~nm}$ ). 


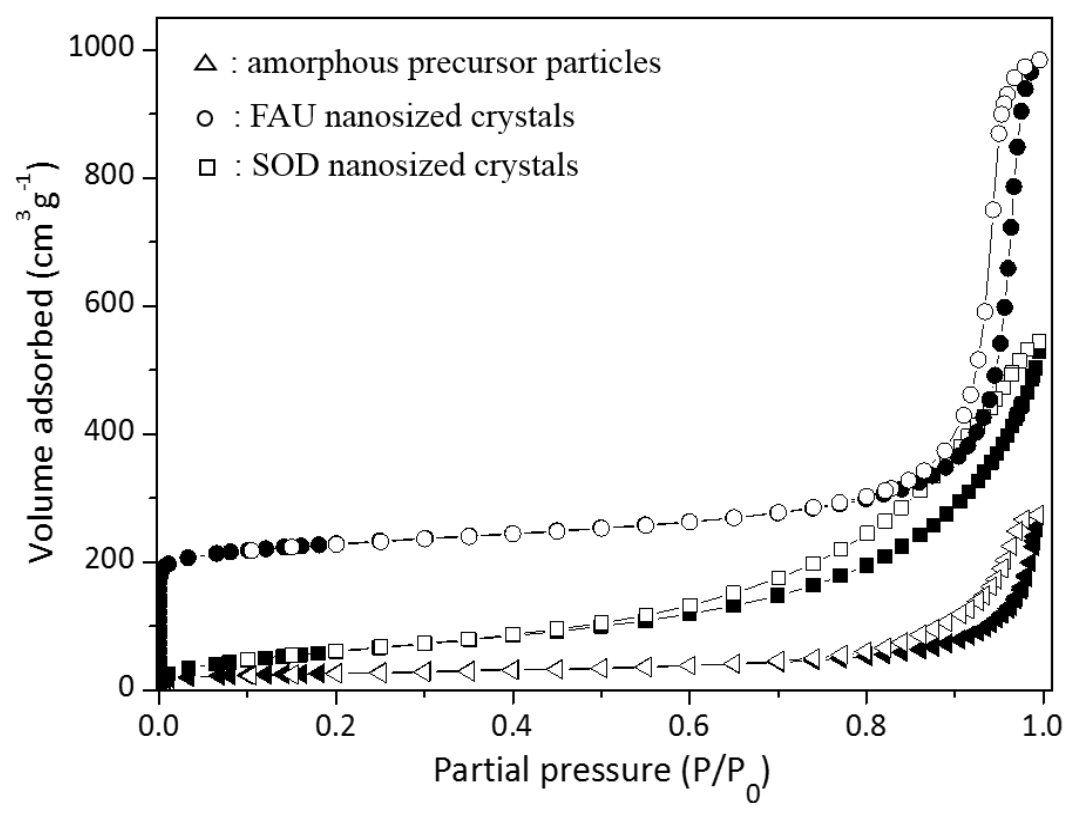

Figure 3. Nitrogen sorption isotherms of amorphous precursor nanoparticles, FAU and SOD nanosized crystals. 


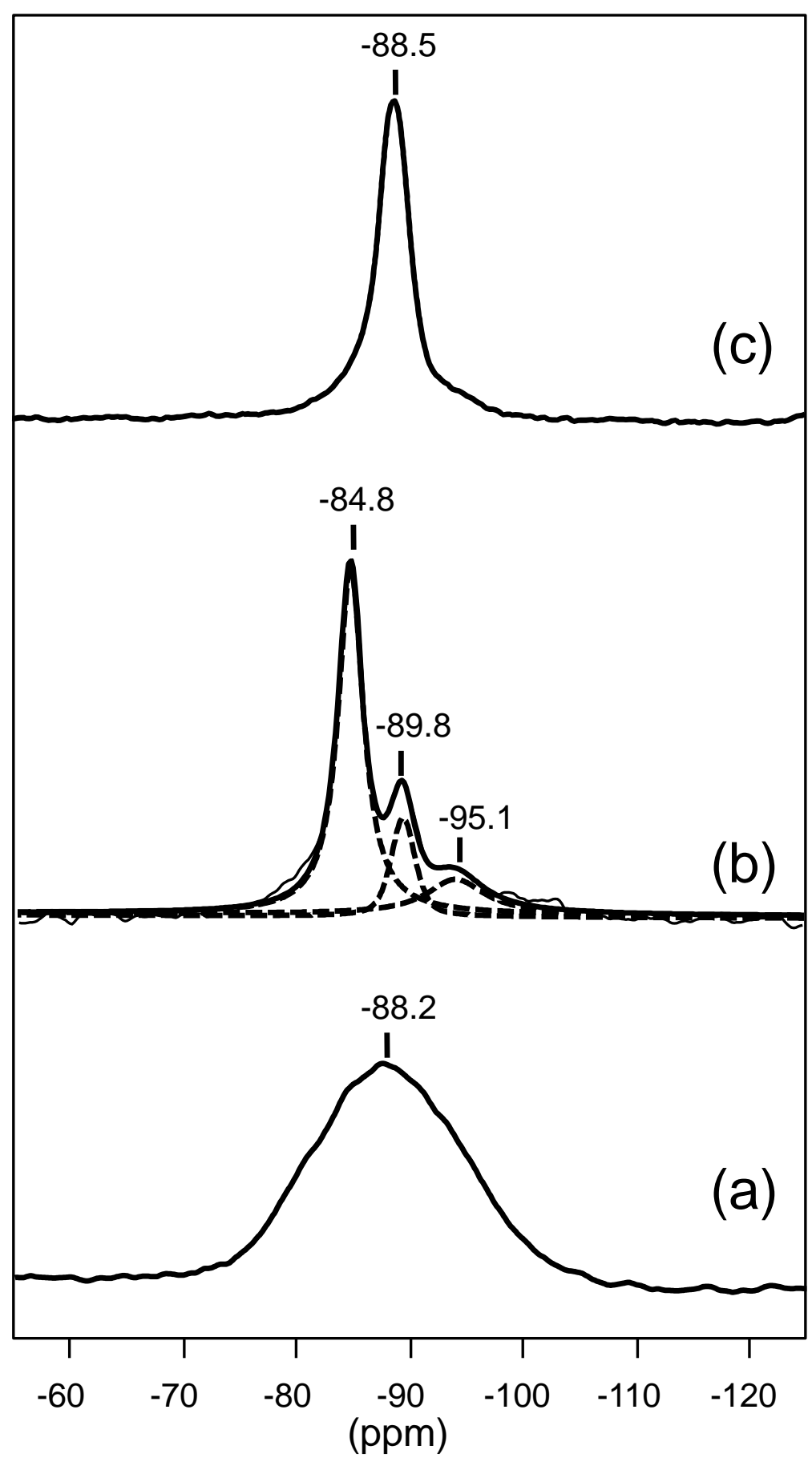

Figure 4. ${ }^{29} \mathrm{Si}$ NMR spectra of (a) amorphous precursor nanoparticles, (b) FAU and (c) SOD nanosized crystals. 


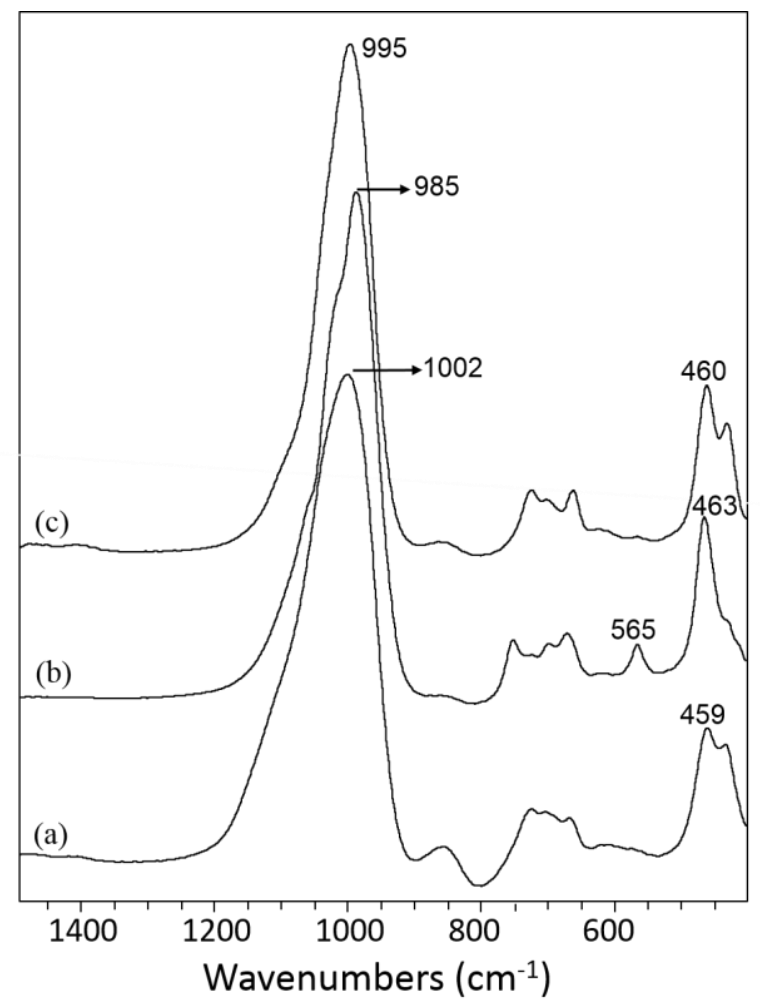

Figure 5. IR spectra of (a) amorphous precursor nanoparticles, (b) FAU and (c) SOD nanocrystals. 

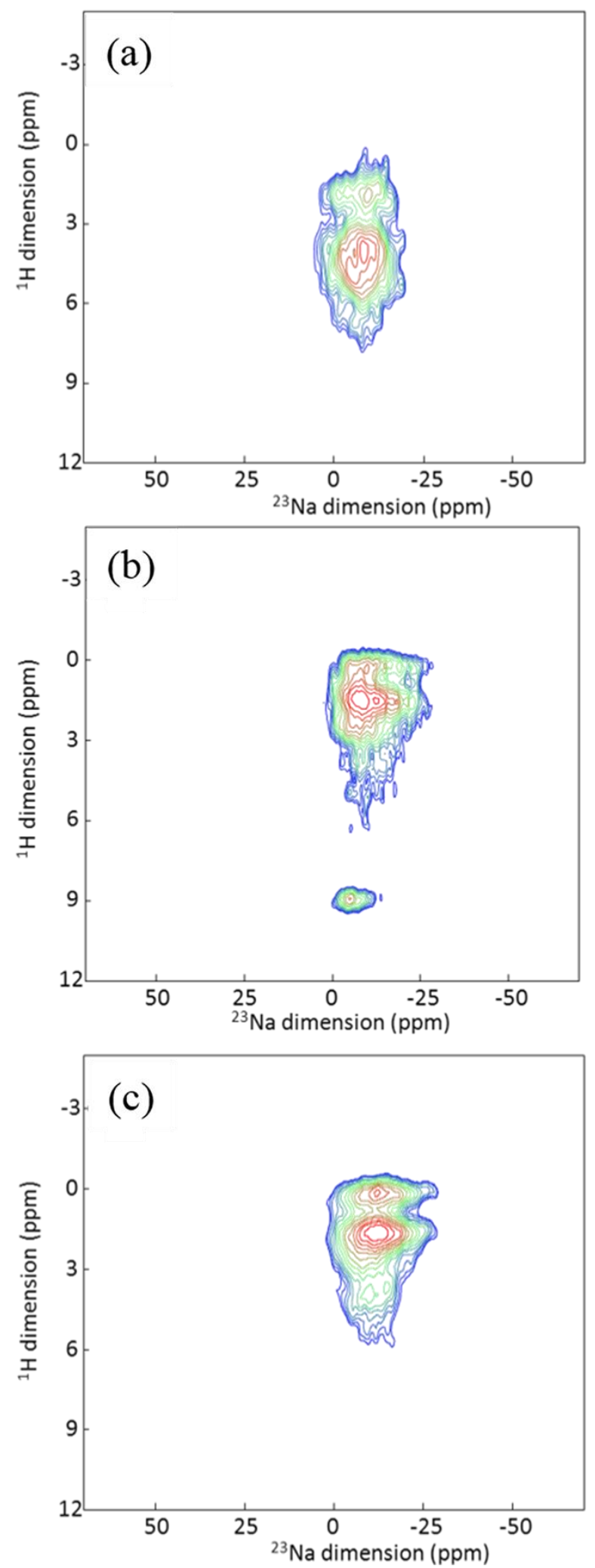

Figure 6. ${ }^{23} \mathrm{Na}-{ }^{1} \mathrm{H}$ MAS D-HMQC NMR spectra of (a) amorphous precursor nanoparticles, (b) SOD and (c) FAU nanosized crystals. All samples were dehydrated at $250{ }^{\circ} \mathrm{C}$ under vacuum prior to measurement. 

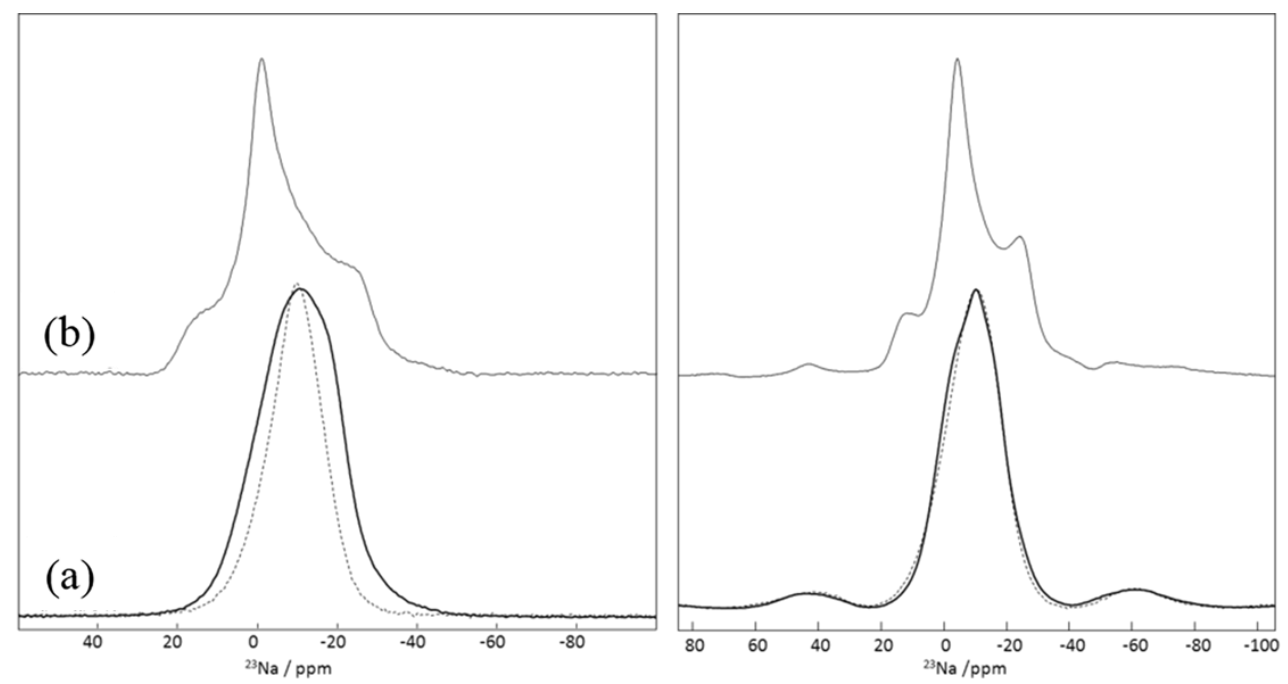

Figure 7. ${ }^{23} \mathrm{Na}$ MAS NMR spectra of (a) amorphous precursor nanoparticles (dash lines) and FAU nanosized zeolite (thick line) and (b) SOD nanosized crystals. Left: NMR spectra recorded at room temperature and $20.0 \mathrm{~T}$. Right: NMR spectra recorded at $-173{ }^{\circ} \mathrm{C}$ and $18.8 \mathrm{~T}$. All samples were dehydrated at $250{ }^{\circ} \mathrm{C}$ under vacuum prior to measurement. 
Table 1. List of samples prepared by treatment of amorphous precursor nanoparticles with alkali solutions.

\begin{tabular}{|c|c|c|c|c|}
\hline Sample & $\begin{array}{c}\text { Concentration of } \\
\mathrm{NaOH}(\mathrm{LiOH} / \mathrm{KOH})\end{array}$ & Solid/ Liquid ratio & $\begin{array}{c}\text { Synthesis temperature } \\
\text { /time }\end{array}$ & Phase \\
\hline S1 & 0 wt.\% & -- & -- & Amorphous \\
\hline S2 & 5 wt. $\% \mathrm{NaOH}$ & 0.05 & $60^{\circ} \mathrm{C} / 20 \mathrm{~h}$ & FAU \\
\hline S3 & 23 wt.\% $\mathrm{NaOH}$ & 0.05 & $60^{\circ} \mathrm{C} / 40 \mathrm{~h}$ & SOD \\
\hline S4 & 5 wt.\% LiOH & 0.05 & $60^{\circ} \mathrm{C} / 20 \mathrm{~h}$ & Amorphous \\
\hline S5 & 5 wt.\% KOH & 0.05 & $60^{\circ} \mathrm{C} / 20 \mathrm{~h}$ & Amorphous \\
\hline S6 & $\begin{array}{c}5 \text { wt. } \% \mathrm{KOH}+5 \text { wt. } \% \\
\mathrm{NaOH}\end{array}$ & 0.05 & $60^{\circ} \mathrm{C} / 20 \mathrm{~h}$ & FAU \\
\hline S7 & $\begin{array}{c}5 \text { wt. \% } \mathrm{LiOH}+5 \text { wt. } \% \\
\mathrm{NaOH}\end{array}$ & 0.05 & $60^{\circ} \mathrm{C} / 20 \mathrm{~h}$ & FAU \\
\hline
\end{tabular}




\section{Supporting Information}

Transformation of Discrete Amorphous Aluminosilicate Nanoparticles into Nanosized Zeolites

Hailing Guo, ${ }^{\circ}$ Lei Zhao, ${ }^{\circ}$ Charlotte Martineau-Corcos, Franck Fayon, Jasmine Viger-Gravel, Hussein Awala, Philippe Boullay, Julien Grand, Aurélie Vicente, Jean-Pierre Gilson, and Svetlana Mintova*

I. Supporting figures

II. Supporting tables 


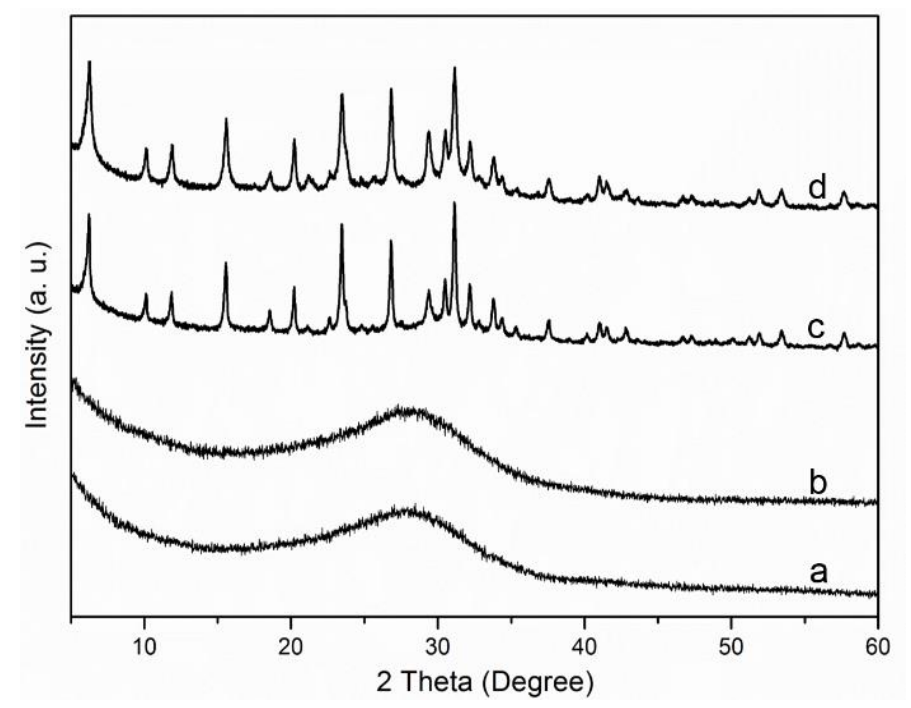

Figure S1. XRD patterns of samples synthesized under treatment with (a) 5 wt.\% $\mathrm{LiOH}$, (b) 5 wt. $\% \mathrm{KOH}$, (c) mixture of $5 \mathrm{wt} \% \mathrm{LiOH}$ and $5 \mathrm{wt} . \% \mathrm{NaOH}$, and (d) mixture of $5 \mathrm{wt} . \% \mathrm{KOH}$ and 5 wt. $\% \mathrm{NaOH}$. 
(a)

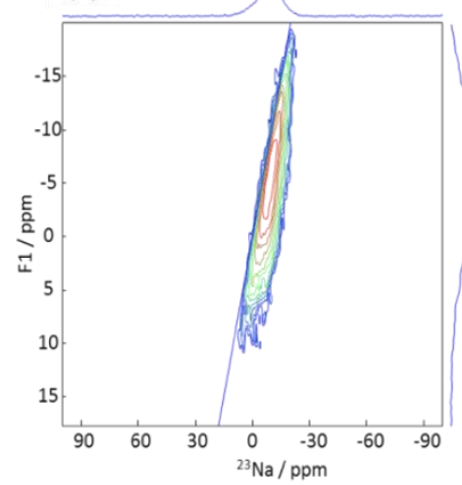

(b)

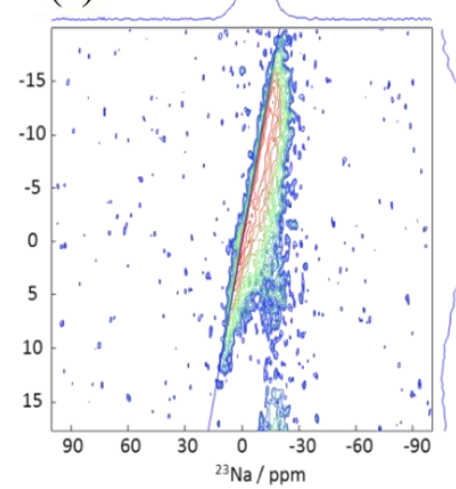

(c)

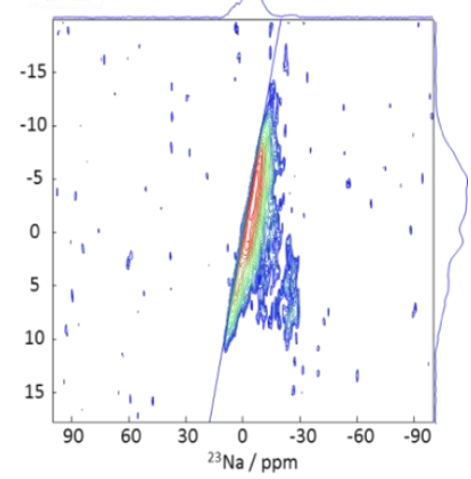

Figure S2. ${ }^{23} \mathrm{Na}$ MQMAS NMR spectra of (a) amorphous precursor nanoparticles, (b) FAU and (c) SOD nanocrystals dehydrated at $250{ }^{\circ} \mathrm{C}$ recorded at $20.0 \mathrm{~T}$. 

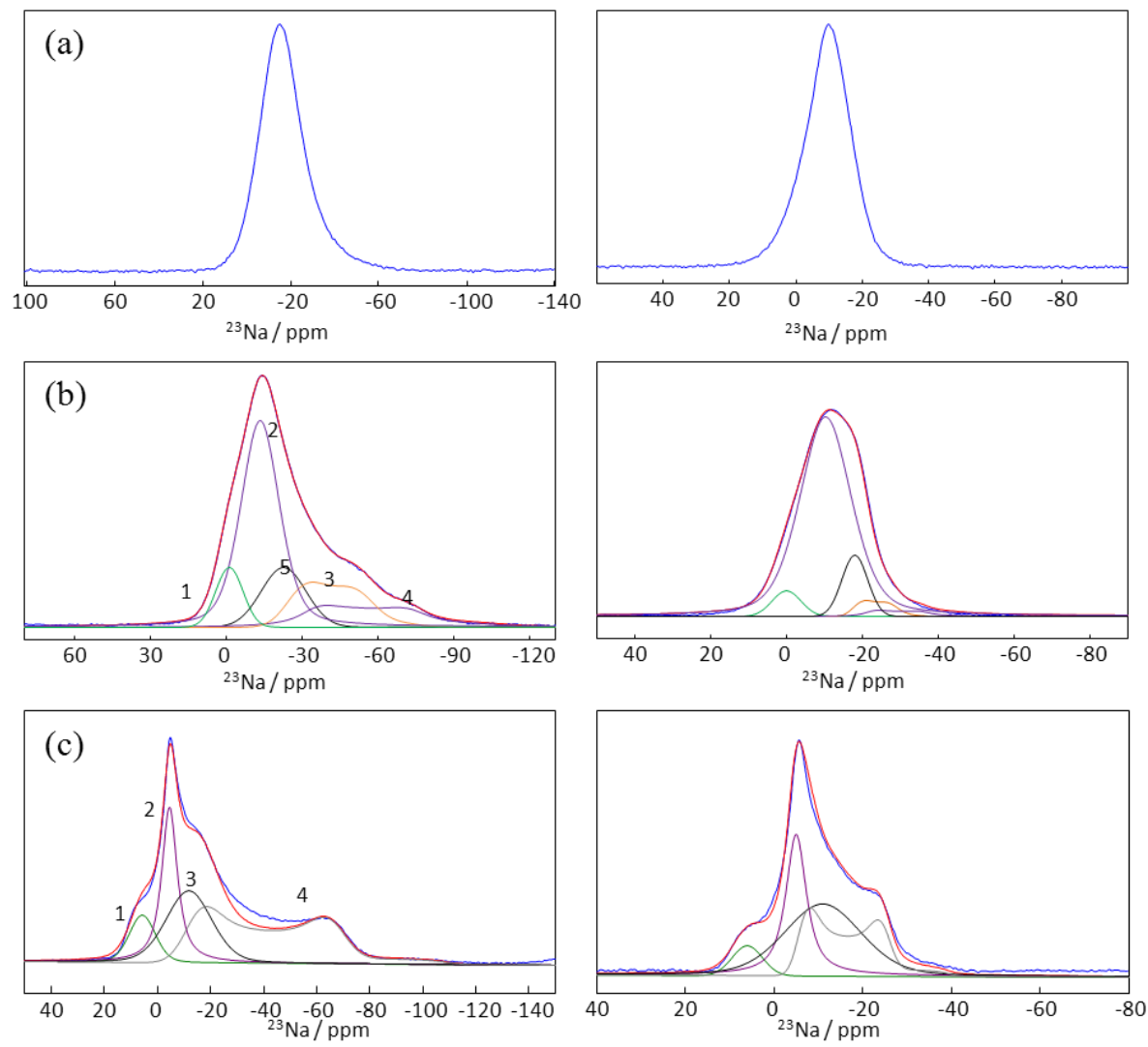

Figure S3. Room temperature ${ }^{23} \mathrm{Na}$ MAS NMR spectra of (a) amorphous precursor particles, (b) FAU and (c) SOD nanocrystals dehydrated at $250^{\circ} \mathrm{C}$ recorded at $11.7 \mathrm{~T}$ (left) and $20.0 \mathrm{~T}$ (right). The deconvolutions of the spectra of FAU and SOD are shown. For each resonance, the same values of isotropic chemical shift $\delta_{\text {iso }}$, quadrupolar coupling constant $\mathrm{C}_{\mathrm{Q}}$ and asymmetry parameters $\eta_{\mathrm{Q}}$ were used at both fields. The linewidths (which are larger at $20 \mathrm{~T}$ ) and amplitudes were allowed to vary. Differences between relative intensities of the individual ${ }^{23} \mathrm{Na}$ resonances at the two magnetic fields are attributed to variation of ${ }^{23} \mathrm{Na}$ relaxation times with the magnetic field. 


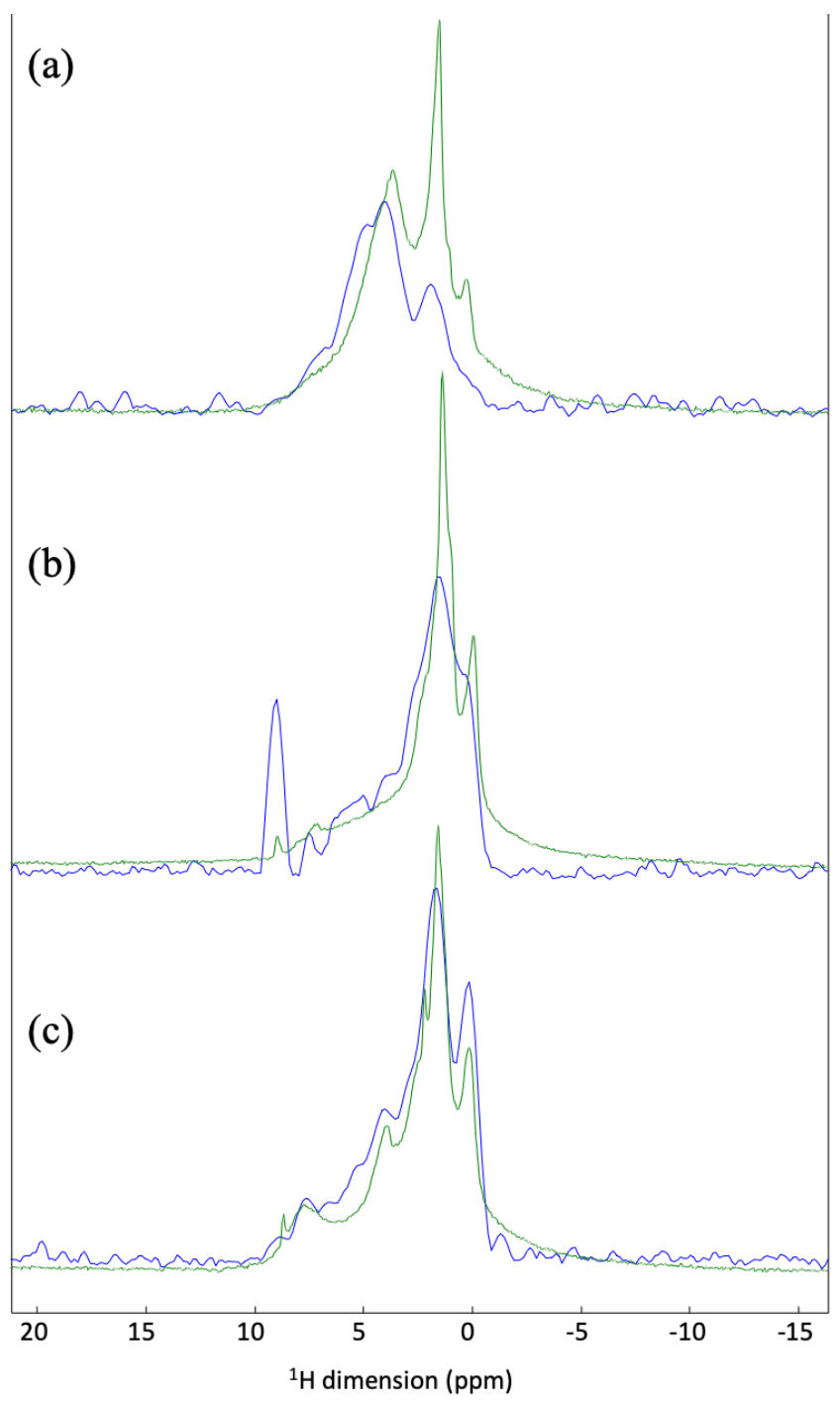

Figure S4. MAS ${ }^{1} \mathrm{H}$ (green) and ${ }^{1} \mathrm{H}$ projection of the ${ }^{23} \mathrm{Na}-{ }^{1} \mathrm{H} D$-HMQC NMR spectra (blue) of (a) amorphous particles, (b) SOD and (c) FAU samples. 


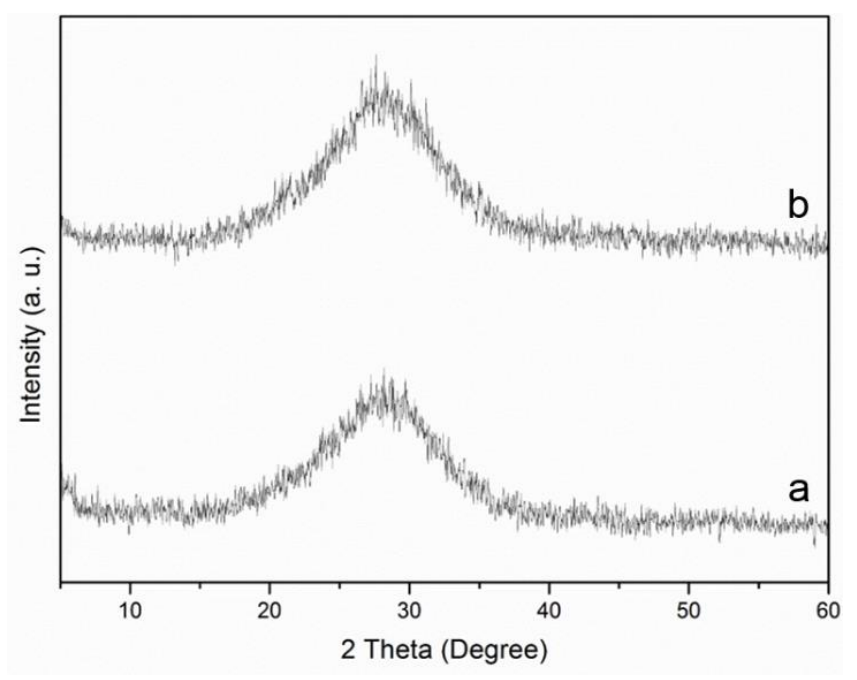

Figure S5. XRD patterns of amorphous precursor nanoparticles (a) without aging and (b) after aging, subjected to treatment with $5 \mathrm{wt} \% \mathrm{NaOH}$ at $60^{\circ} \mathrm{C}$ for $20 \mathrm{~h}$. 
Table S1. Chemical composition of amorphous precursor nanoparticles, FAU and SOD nanosized zeolites determined by ICP, ${ }^{29} \mathrm{Si}$ NMR and EDS.

\begin{tabular}{cccc}
\hline Sample & Si/Al (ICP) & Si/Al ( ${ }^{29}$ Si NMR) & Si/Al (EDS) \\
\hline Amorphous precursor nanoparticles & 1.8 & -- & 1.9 \\
FAU nanosized crystals (sample S2) & 1.1 & 1.14 & 1.2 \\
SOD nanosized crystals (sample S3) & 1.3 & 1.33 & 1.3 \\
\hline
\end{tabular}

Table S2. Physicochemical properties of amorphous precursor nanoparticles, FAU and SOD nanocrystals determined from $\mathrm{N}_{2}$ sorption measurements. 


\begin{tabular}{cccccc}
\hline Sample & $\begin{array}{c}\mathrm{S}_{\mathrm{BET}} \\
\left(\mathrm{m}^{2} \mathrm{~g}^{-1}\right)\end{array}$ & $\begin{array}{c}\mathrm{V}_{\text {mic }} \\
\left(\mathrm{cm}^{3} \mathrm{~g}^{-1}\right)\end{array}$ & $\begin{array}{c}\mathrm{V}_{\text {mes }} \\
\left(\mathrm{cm}^{3} \mathrm{~g}^{-1}\right)\end{array}$ & $\begin{array}{c}\mathrm{S}_{\mathrm{ext}} \\
\left(\mathrm{m}^{2} \mathrm{~g}^{-1}\right)\end{array}$ & $\begin{array}{c}\mathrm{V}_{\text {tot }} \\
\left(\mathrm{cm}^{3} \mathrm{~g}^{-1}\right)\end{array}$ \\
\hline $\begin{array}{c}\text { Amorphous precursor } \\
\text { nanoparticles }\end{array}$ & 235 & 0.00 & 0.61 & 260 & 0.61 \\
$\begin{array}{c}\text { FAU nanosized } \\
\text { crystals (sample S2) }\end{array}$ & 850 & 0.31 & 1.05 & 230 & 1.36 \\
$\begin{array}{c}\text { SOD nanosized } \\
\text { crystals (sample S3) }\end{array}$ & 160 & 0.00 & 0.43 & 160 & 0.43 \\
\hline
\end{tabular}


Table S3. NMR parameters used for the deconvolution of the ${ }^{23} \mathrm{Na}$ MAS NMR spectra of FAU and SOD nanocrystals recorded at 11.7 and $20.0 \mathrm{~T}$. Resonances 1, 2, 5 in FAU and 1, 2, 3 in SOD are modeled with Gaussian lines. Their linewidth reflects the chemical shift distribution (which is larger at higher field). Resonances 3, 4 in FAU and 4 in SOD are modeled with second-order quadrupolar line shapes.

\begin{tabular}{|c|c|c|c|c|c|c|}
\hline Sample & Line & $\begin{array}{c}\delta_{\text {iso }} \\
(\mathrm{ppm})\end{array}$ & $\begin{array}{l}\text { Linewidth at } \\
20.0 \mathrm{~T}(\mathrm{~Hz})\end{array}$ & $\begin{array}{c}\text { Linewidth at } \\
11.7 \mathrm{~T}(\mathrm{~Hz})\end{array}$ & $\begin{array}{c}\mathrm{C}_{\mathrm{Q}} \\
(\mathrm{MHz})\end{array}$ & $\eta_{Q}$ \\
\hline \multirow{5}{*}{$\begin{array}{c}\text { Nanosized FAU } \\
\text { crystals } \\
\text { (sample S2) }\end{array}$} & 1 & 0 & 2024 & 1680 & -- & -- \\
\hline & 2 & -10 & 3598 & 2376 & -- & -- \\
\hline & 3 & -16 & -- & -- & 3.96 & 0 \\
\hline & 4 & -18 & -- & -- & 4.85 & 0 \\
\hline & 5 & -18 & 1800 & 3600 & -- & -- \\
\hline \multirow{4}{*}{$\begin{array}{l}\text { Nanosized SOD } \\
\text { crystals (sample } \\
\text { S3) }\end{array}$} & 1 & 6 & 1807 & 1536 & -- & -- \\
\hline & 2 & -5 & 1237 & 926 & -- & -- \\
\hline & 3 & -11 & 4564 & 2684 & -- & -- \\
\hline & 4 & 1 & -- & -- & 5.58 & 0.05 \\
\hline
\end{tabular}

